\title{
Parametric estimation of time varying baselines in airborne interferometric SAR
}

\author{
Mohr, Johan Jacob; Madsen, Søren Nørvang
}

Published in:

Proceedings of the International Geoscience and Remote Sensing Symposium

Link to article, DOI:

10.1109/IGARSS.1996.516440

Publication date:

1996

Document Version

Publisher's PDF, also known as Version of record

Link back to DTU Orbit

Citation (APA):

Mohr, J. J., \& Madsen, S. N. (1996). Parametric estimation of time varying baselines in airborne interferometric SAR. In Proceedings of the International Geoscience and Remote Sensing Symposium: Remote Sensing for a Sustainable Future (Vol. Volume 1, pp. 677-679). IEEE. https://doi.org/10.1109/IGARSS.1996.516440

\section{General rights}

Copyright and moral rights for the publications made accessible in the public portal are retained by the authors and/or other copyright owners and it is a condition of accessing publications that users recognise and abide by the legal requirements associated with these rights.

- Users may download and print one copy of any publication from the public portal for the purpose of private study or research.

- You may not further distribute the material or use it for any profit-making activity or commercial gain

- You may freely distribute the URL identifying the publication in the public portal 


\title{
Parametric Estimation of Time Varying Baselines in Airborne Interferometric SAR
}

\author{
Johan Jacob Mohr, Søren Nørvang Madsen \\ Danish Center for Remote Sensing, Dept. of Electromagnetic Systems \\ Technical University of Denmark, B-348, DK-2800 Lyngby, Denmark \\ Phone: +45 4525 3800, Fax: +45 4593 1634, Email: jm@emi.dtu.dk
}

\begin{abstract}
In this paper a method for estimation of time varying spatial baselines in airborne interferometric Synthetic Aperture Radar (SAR) is described. The range and azimuth distortions between two images acquired with a non-linear baseline are derived. A parametric model of the baseline is then, in a least square sense, estimated from image shifts obtained by cross correlation of numerous small patches throughout the image. The method has been applied to airborne EMISAR ${ }^{\dagger}$ imagery from the 1995 campaign over the Storstrømmen Glacier in North East Greenland conducted by the Danish Center for Remote Sensing ${ }^{\dagger}$. This has reduced the baseline uncertainties from several meters to the centimeter level in a $36 \mathrm{~km}$ scene. Though developed for airborne SAR the method can easily be adopted to satellite data.
\end{abstract}

\section{INTRODUCTION}

The application of repeat pass interferometric techniques to airborne SAR imagery, though very similar to satellite interferometry, comprises quite different problems with respect to baseline estimation. During data acquisition an airplane, as opposed to a satellite, continuously has to be controlled to ensure a proper spatial baseline. The airborne EMISAR is in the repeat pass mode controlled via the Instrument Landing System (ILS) by the radar control computer which again receives navigational information from a P-code GPS receiver.

The actual trajectory is typically oscillating around the desired track and the deviations must be compensated in the processing and taken into account in the interpretation of the interferograms. The high frequency motion components can be accurately measured by an Inertial Navigation Unit (INU), but this measurement has to be augmented for baseline estimations due to drift. The meter level absolute accuracy provided by $\mathrm{P}$-code GPS utilized by EMISAR is far from the requirement, but even the decimeter accuracy potential with differential GPS is not sufficiently accurate.

$\dagger$ Development of the EMISAR was sponsored by the Thomas B. Thriges Foundation, the Danish Technical Research Counsil (STVF), the Royal Danish Air Force (RDAF), the Technical University of Denmark and the Joint Research Centre (JRC).

$\dagger^{\dagger}$ The Danish Center for Remote Sensing is established and funded by the Danish National Research Foundation.
The required accuracy for the baseline knowledge is dependent on the application on the order of sub millimeter to centimeters.

A method for estimation of the linear terms (azimuth offset, skew and stretch) on the basis of radar data is described in [1]. This method is generalized here and a third order polynomial error model, corresponding to an INU with a linearly varying drift in the acceleration biases, is investigated. Experiments with EMISAR data from Storstrømmen, though, tends to suggest that second order polynomials is sufficient.

The INU measurements also requires synchronization with radar data. In the EMISAR system an internal $9 \mathrm{~ms}$ delay in the INU has also been estimated on the basis of a co-registration of the images.

\section{MODEL}

For simplicity the problem is here described in a rectangular coordinate system, $(s, c, h)$, where $\mathrm{s}$ is the along track coordinate, $c$ across track (positive to the left) and $h$ is up.

Track 1 is assumed to be a straight line at an altitude, $H$, with a constant sample spacing, see Fig. 1a. The baseline to be estimated is the displacement of track 2 relative to track 1 . Thus, track 2 is given by $(s(t), c(s), H+\mathrm{h}(s))$, where $c(s)$ and $h(s)$ constitutes the spatial baseline. What can be measured by a correlation of small patches of the amplitude images is range off-set from track 1 to track $2, n_{\text {ra }}$, and the corresponding azimuth off-sets, $n_{\mathrm{az}}$, in bins. Any pixel coordinate in either of the two images can be converted to slant range distance, $\rho_{i}$, and azimuth position, $s_{i}$, by

$$
\begin{aligned}
& \rho_{1}=\rho_{01}+n_{r a, 1} d r, \\
& \rho_{2}=\rho_{02}+n_{r a, 2} d r, \\
& s_{1}=s_{01}+n_{a z, 1} d a, \\
& s_{2}=s_{02}+n_{a z, 2} d a,
\end{aligned}
$$

where $\rho_{0}$ is slant range to first bin, $s_{0}$ is azimuth of first bin, $d r$ and $d a$ are range and azimuth pixel spacing respectively and the index denotes image number. Since it is assumed that the first image is acquired from a ideal track, $\rho_{1} \equiv k$ and $s_{1} \equiv s$, see Fig. 1. For track 2 we have

$$
\begin{aligned}
& s=s_{2}+\Delta \mathrm{s}\left(s_{2}\right)=s_{2}+\sum_{i=0, n s} \sigma_{i} \mathrm{~T}_{i}\left(s_{2}\right), \\
& \mathrm{c}(s)=\sum_{i=0, n c} \chi_{i} \mathrm{~T}_{i}(s), \\
& \mathrm{h}(s)=\sum_{i=0, n h}^{\sum} \eta_{i} \mathrm{~T}_{i}(s),
\end{aligned}
$$



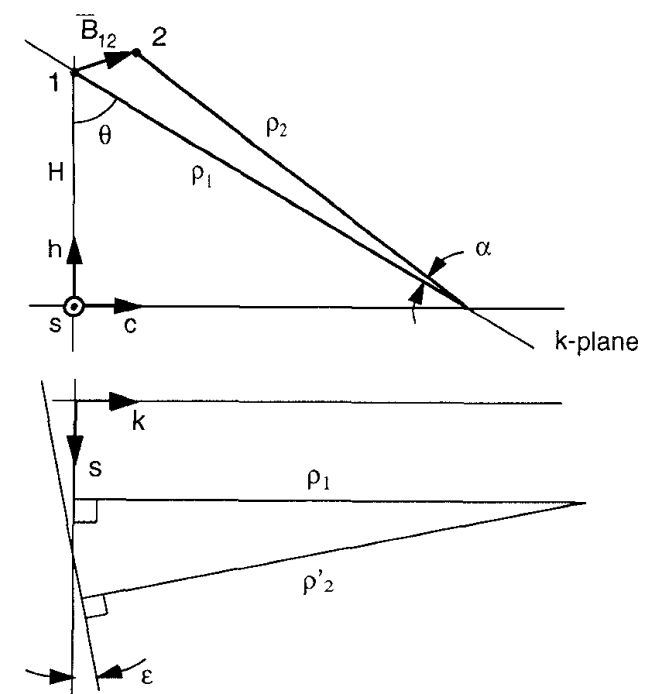

Fig. 1. The geometry a) projected on a plane perpendicular to $\hat{s}$, b) projected on the slant range plane.

where $\sigma_{i}, \chi_{i}$ and $\eta_{i}$ are the unknown coefficients in an decomposition of track 2 in some error functions $\mathrm{T}_{i}(s)$, e.g. a polynomial of degree $i$.

The next step is to express the range and azimuth image off-sets in terms of the unknown baseline parameters. The geometry is projected on a plane perpendicular to the $s$-direction and a projection onto the slant range plane, Fig. 1. The auxiliary angles $\alpha$ and $\varepsilon$ can be determined from

$$
\begin{aligned}
& \sin \alpha=\frac{1}{\rho_{2}}(c \cos \theta+h \sin \theta) \\
& \text { and } \\
& \tan \varepsilon=\frac{\partial c}{\partial s} \sin \theta-\frac{\partial h}{\partial s} \cos \theta .
\end{aligned}
$$

The azimuth shift between the images, readily calculated as

$$
\left[s_{2}+\Delta \mathrm{s}\left(s_{2}\right)\right]-s_{1}=\rho_{2}^{\prime} \sin \varepsilon
$$

are not used directly, but with small $\alpha$ and $\varepsilon$ the equation set for each image point become

$$
\begin{aligned}
& s_{2}-s_{1}=-\Delta s\left(s_{2}\right)+\rho_{2} \cos \alpha\left(\frac{\partial c}{\partial s}(s) \sin \theta-\frac{\partial h}{\partial s}(s) \cos \theta\right),(4) \\
& \rho_{2} \cos \alpha \cos \varepsilon-\rho_{1}=-c(s) \sin \theta+h(s) \cos \theta
\end{aligned}
$$

Finally (1)-(3) and their derivatives are substituted into (4)-(5) forming two independent (virtual) linear equations in the baseline parameters $\sigma_{i}, \chi_{i}$ and $\eta_{i}$. With several well spread estimated image shifts, sets of (4)-(5) will form a equation system with sufficient rank to determine the baseline.

The outlined method gives a well determined baseline estimate, since the azimuth shift is very sensitive to the derivative of $\mathrm{c}(s)$ and $\mathrm{h}(s)$. Also note that the method in principle requires knowledge of the topography (through $\theta$ ), but to first order a flat earth assumption is sufficient.

\section{MOTION COMPENSATION}

In airborne SAR imperfect motion compensation also gives rise to a misregistration of the images. In this section the importance of (unknown) topography and accelerations in $c$ and $h$ is addressed. Imperfections due to unknown topography is considered first. From Fig. 2, the shift, $\Delta p$, to be compensated is seen to be

$$
\Delta \rho=-\hat{n}(\theta) \cdot \bar{b}(s)=-c \sin \theta+h \cos \theta .
$$

A height "error", $\delta_{z}$, will give an uncompensated shift of

$$
\delta_{r a}=\frac{\partial \Delta \rho}{\partial z} \delta_{z}=-(c \cos \theta+h \sin \theta) \frac{1}{\rho \sin \theta} \delta_{z}
$$

in the range direction as compared to an image with perfect compensated motion. Note that the deviation from an actual track to a reference track is compensated by a procedure which is basically similar to how one data set of an interferometric pair is overlaid the other data set. Reversely this relationship between height offsets and slant range offsets is the very reason that interferometry works, [2]. An unknown scene height also give rise to a shift in the azimuth direction,

$$
\delta_{a z}=\frac{\partial}{\partial z}\left(\rho \frac{\partial \Delta \rho}{\partial s}\right) \delta_{z}=-\left(\frac{\partial c}{\partial s} \cos \theta+\frac{\partial h}{\partial s} \sin \theta\right) \frac{1}{\sin \theta} \delta_{z},
$$

in generale much larger, but not as severe in the sense that it does not affect the phase. On the other hand it is most undesirable since it causes misalignment of the images. The cross track velocities must therefore be minimized, during the control of the airplane. Note that it is the absolute heights which are of importance - not the variations within the scene.

Another important issue is delay of navigation data relative to the radar data. Such a delay results in an error in the measurement of the antenna phase center. This delay will mainly cause a shift in the azimuth direction and thus cause misalignment of the data sets. If the delay, $\delta_{s}$, is measured in meter $\left(=v t_{\text {delav }}\right)$ the shift is

$$
\delta_{a z}=\frac{\partial}{\partial s}\left(\rho \frac{\partial \Delta \rho}{\partial s}\right) \delta_{s}=\left(-\frac{\partial^{2} c}{\partial s^{2}} \sin \theta+\frac{\partial^{2} h}{\partial s^{2}} \cos \theta\right) \rho \delta_{s} .
$$

It is therefore of importance that the accelerations in the control of the airplane is minimized. On the other hand (8) enables the estimation of the delay as two independent aircraft tracks generally will have a baseline acceleration.

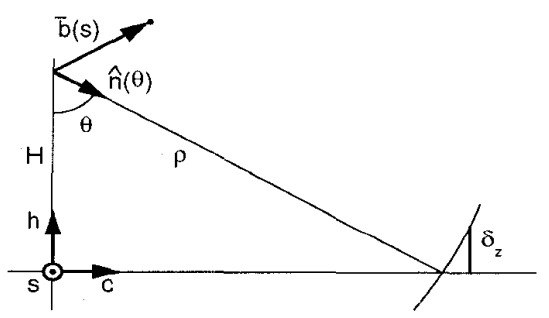

Fig. 2. Motion compensation of a target at height $\delta_{z} . \hat{n}(\theta)$ is the LOS unit vector; $\mathrm{b}(s)$ deviation from the reference track. 


\section{RESULTS}

DCRS has on two consecutive days in august 1995 acquired L-band $(\mathrm{HH}+\mathrm{VV})$ repeat track interferometry data over Storstrømmen glacier in Northeast Greenland. The nominally $36 \mathrm{~km}$ long imagery were acquired from an altitude of $H=12500 \mathrm{~m}$ with incidence angles ranging from $26^{\circ}$ to $58^{\circ}$.

Two typical tracks with a perpendicular baseline of about $10 \mathrm{~m}$ were selected to illustrate the three step baseline estimation procedure. The navigation data and the radar data are synchronized via an accurate time tagging. Local image misregistrations are found by a cross correlation of 25 range patches by 79 azimuth patches with a size of $128 \times 128$ pixels.

1. Initial processing of the two data sets with motion compensation to a common reference line. Cross correlation. Estimation of the linear baseline residuals by solving equations (4) and (5) in a least squares sense, see Table 1. Correction of the navigation data.

2. Reprocessing and cross correlation. The misregistrations are shown on Fig. 3. Now a third order model is fitted, and a navigation data delay of $3 \mathrm{~ms}$ estimated by an application of (8).

3. Reprocessing and cross correlation. A third order model is again fitted, see Table 1, The navigation data are corrected and the baselines can now be extracted.

For verification a final processing and cross correlation has been performed and the results plotted on Fig. 3, and it is seen that the higher order baseline terms significantly reduce the registration errors. The third order terms are significant in a F-test on all reasonable levels. If the apparent remaining systematic errors are taken into account, e.g, by a factor 10 reduction in number of independent observations in the F-test, the third order terms are significant only on the $90 \%$ level, thus being obvious subjects for elimination.

The accuracy of the estimated baseline is addressed via an analysis of the dispersion matrix of the estimated 'baseline residual coefficients.' The standard deviations on the sum off the cross track coefficients, $\chi_{0}-\chi_{3}$ and $\eta_{0}-\eta_{3}$, are $1.4 \mathrm{~cm}$ and $1.7 \mathrm{~cm}$ respectively, (with an assumption of complete uncorrelated misregistrations).

Table 1. Estimated baseline residual after first and third processing. Residuals is expressed as in (1)-(3), where $T_{i}(s)$ is an $i$-order Chebychev polynomial with $s$ scaled to $[-1 ; 1]$.

\begin{tabular}{|c|c|c|c|}
\hline \hline$i$ & $\sigma_{i}[\mathrm{~m}]$ & $\chi_{i}[\mathrm{~m}]$ & $\eta_{i}[\mathrm{~m}]$ \\
\hline \hline 0 & -1.246 & -6.363 & -11.978 \\
1 & 0.989 & -0.802 & 1.168 \\
\hline \multicolumn{3}{|l|}{ Std. dev. ra-residual: } & $0.221[\mathrm{~m}]$ \\
Std. dev. az-residual: & & $0.781[\mathrm{~m}]$ \\
\hline \hline 0 & -0.374 & -0.154 & -0.004 \\
1 & -1.858 & -0.006 & -0.003 \\
2 & -1.151 & -0.488 & -0.017 \\
3 & 0.031 & 0.016 & 0.021 \\
\hline Std. dev. ra-residual: & & $0.044[\mathrm{~m}]$ \\
Std. dev. az-residual: & & $0.133[\mathrm{~m}]$ \\
\hline \hline
\end{tabular}
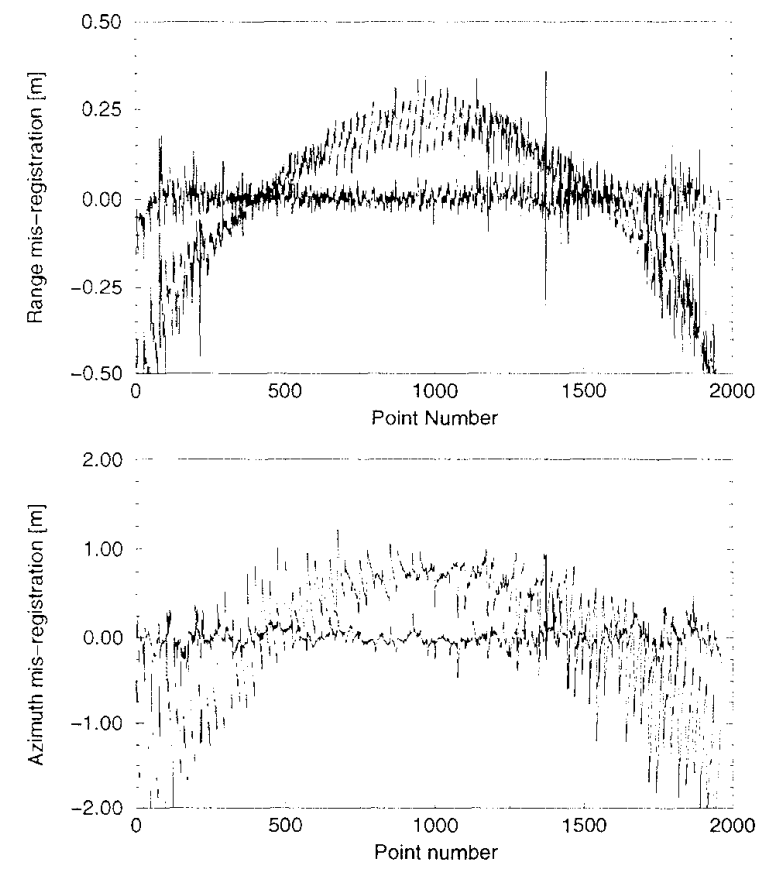

Fig. 3. The range and azimuth misregistrations after removal of the linear (parabolic curves) and the 3 'rd order (flat curves) baselines errors. The patches are numbered consecutively.

\section{CONCLUSION}

Track estimation as well as navigation data synchronization have been shown to reduce uncertainties on the baseline from several meters to centimeter level in the typically $36 \mathrm{~km}$ long EMISAR imagery of Storstrømmen. Though accurate enough for some applications, for others it might be necessary to take motion compensation errors into account in the estimation scheme, via a coarse DEM. Alternatively, Kiruma has proposed a multi track technique for stationary scenes, which are easily modifed to take higher order motion components into account, [3]. However, this does not utilize the azimuth distortions which contains useful information and must be taken into account in the airborne case.

\section{REFERENCES}

[1] Søren N. Madsen and Howard Zebker, "Imaging Radar Interferometry", chapter 17 in Manual of Remote Sensing, Vol. III, chapter 17,1996 , in press

[2] David R. Stevens, Ian G. Cumming, and A. Lawrence Gray, "Options for Airborne Interferometric SAR Motion Compensation", IEEE Trans. GRS, vol. 33, pp. 409-420, March 1995.

[3] Kimura, Hiroshi, "A Method to Estimate Baseline and Platform Altitude for SAR Interferometry", Proceedings of IGARSS'95, pp. 199-201, Firenze, Italy, July 1995. 